\title{
Supply Chain Finance Credit Risk and Its Establishment on Evaluation Index System
}

\author{
Deai Deng \\ Hunan Vocational College of Modern Logistics, Changsha, 410131, China
}

Keywords: supply chain finance, credit risk, evaluation index system, risk characteristics, risk analysis

\begin{abstract}
Based on scientific and reasonable index system, the scientific evaluation of the location plan of the city logistics center and the construction of the logistics center in the best city location will play an important role in optimizing transportation routes, reducing logistics costs, improving operational efficiency and promoting urban development. This paper, based on the theory of location of city logistics center, expounds the function of city logistics center, points out the principle of site selection of city logistics center, constructs the architecture model of evaluation index system, and gives a brief description of the evaluation index system. The final evaluation index system consists of six first-level indicators such as infrastructure, economic factors, social factors, natural environment, logistics costs and business environment, and four second-level indicators under each first-level indicator.
\end{abstract}

\section{Introduction}

Many small and medium-sized enterprises play an important role in the supply chain. However, due to the small assets, poor solvency and the low transparency of financial information, financing becomes a problem, resulting in poor flow of funds, information flow and logistics in the supply chain. Even "broken chain" will appear, reducing the overall competitiveness of the supply chain. In this context, in order to better meet customer needs, banks conduct business innovation, promote the supply chain financial model, and explore the SME financing market. Based on the supply chain financial model, banks take advantage of the structural features of the entire chain to accurately grasp the entire trading point of the chain, relying on the core business to provide credit services to small-and-medium-sized enterprises in the chain, enabling more small-and-medium-sized enterprises to enter the capital market, banks to increase profits. At the same time, it has alleviated the capital problems of small and medium-sized enterprises, ensured the smooth operation of the supply chain and enhanced the overall competitiveness of the supply chain.

Risk management is the core issue of financial management. Credit risk is the most important issue in risk management. With the expansion of credit transactions, credit risk is also increasing. Major banks have launched the financing model for supply chain finance. Behind the huge supply chain financial market, banks have not enough understanding of the credit risk of supply chain finance. The recognition, evaluation and control of credit risk are not perfect, which hinders the supply Chain finance promotion and innovation. This article analyzes the credit risk of supply chain finance, constructs the index system of information risk evaluation, provides support for the effective control of supply chain financial credit risk, and promotes the healthy development of supply chain finance.

\section{Definition on Basic Concepts}

The definition of basic concepts is not only related to the selection of research objects, but also to the scope of application of research results. The definition methods include abstract definition and operational definition. This study includes the following basic concepts:

(1) Supply chain. Supply chain is around the core business, through the business flow, information flow, logistics, capital flow control, starting from the procurement of raw materials to 
make the intermediate products and final products, the final sales network to send the products to consumers, by the supplier, Manufacturers, distributors, retailers linked to the end-user function of the overall structure of the chain structure. Supply chain management philosophy is from the consumer's point of view, through collaboration between enterprises, to seek the overall supply chain optimization.

(2) Supply Chain Finance ${ }^{[1]}$. Banks around the core business, management of upstream and downstream SME capital flow and logistics, and the uncontrollable risk of a single enterprise into a supply chain business as a whole can control the risk, through three-dimensional access to various types of information, the risk control in the lowest Financial Services. Supply chain finance reduces the financing threshold for small-and-medium-sized enterprises, effectively supports the effectiveness of capital flows of small-and-medium-sized enterprises, improves the utilization efficiency of working capital and promotes the healthy development of small-and-medium-sized enterprises.

(3) Credit risk. This study is based on the credit risk of commercial banks, generally refers to the borrower unable or unwilling to perform the contract, do not assume due debt obligations, resulting in possibility of bank losses, including the borrower or counterpart default leads to the possibility of loss, including the borrower or counterpart credit rating changes, performance ability the change, which leads to the change of the market value of its debt caused by the loss ${ }^{[2]}$.

(4) Evaluation index system. The evaluation index system refers to the organic whole formed by multiple indicators that characterize various aspects of the evaluation object and their interrelationships and is usually expressed in a hierarchical structure. The highest level represents the general goal of the system. The middle tier represents the intermediate links that achieve the overall goal. There may be multiple levels according to the size and complexity of the scale of the problem. The lowest level indicates the measures, decisions or programs to be selected for achieving the goal.

\section{Operation Process on Supply Chain Finance}

Supply chain finance involves not only borrowing companies and banks, but also the guarantee activities of core enterprises and the services of logistics enterprises. Supply chain finance operation process shown in Fig 1.

The credit risk of enterprises based on supply chain finance is different from the credit evaluation of traditional bank loans. It not only needs to consider the unilateral behavior of borrowing enterprises, but also consider the overall operation during the operation of supply chain. The target of bank credit measurement is the operation status of the entire supply chain finance. The close connection between all parties involved and the credit risk of any one party will bring fluctuations to the whole supply chain. From the perspectives of borrowing enterprises (upstream and downstream small-and-medium-sized enterprises), core enterprises and logistics enterprises, banks analyze the credit risk factors that may lead to the fulfillment of supply chain responsibilities by all parties, taking into account the specific circumstances of the overall supply chain transactions.

\section{Characteristics on Supply Chain Finance Credit Risk}

Although both traditional credit risk and supply chain financial credit risk are caused by information asymmetry, the credit risk of supply chain has the following characteristics because of different credit arrangements ${ }^{[3,4]}$ :

(1) Supply chain financial credit risk includes not only the risk of financing enterprise's own qualification and credit, but also the factors such as the core enterprise, the assets under the transaction and the overall condition of the supply chain operation, which cause the risk of the bank losing due to the default of the enterprise. Supply chain finance credit risk is no longer a single business risk, or the risk of the entire supply chain, a business default, will have an impact on other businesses. 
(2) The operational flow of supply chain finance is more complicated than that of traditional bank credit. The main participants of supply chain financial business include banks, financing enterprises, core enterprises and third-party logistics enterprises, forming a multiple principal-agent relationship. Therefore, the factors that affect the credit risk of supply chain finance are more complicated than the traditional influencing factors.

(3) Supply chain finance reduces indefiniteness by introducing self-compensating technology. The assets under the transaction are the first source of repayment, which determines that the bank must implement a more stringent Risk control means to control logistics and cash flow.

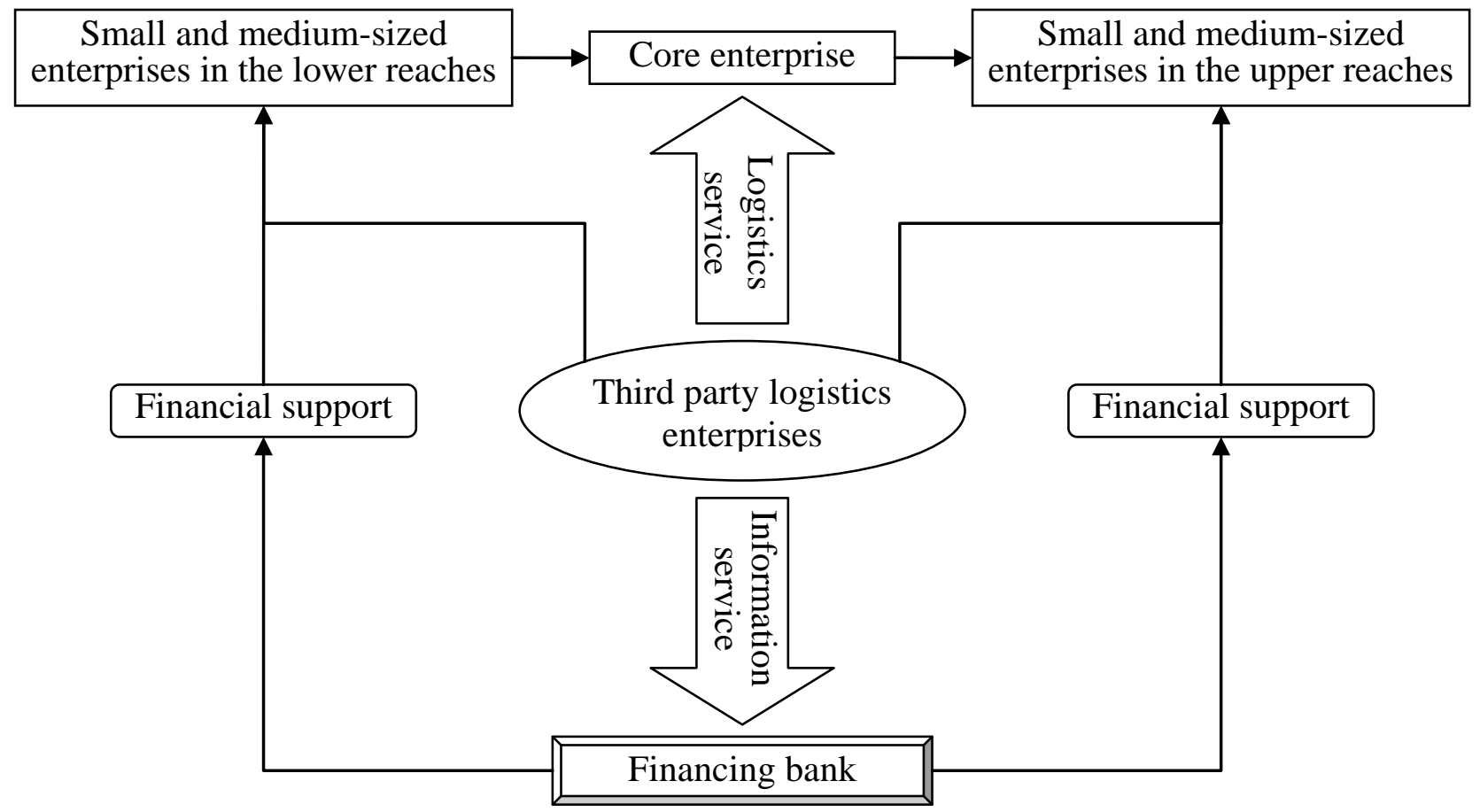

Fig 1 Operation process on supply chain finance

\section{Analysis on Supply Chain Finance Credit Risk}

There are many factors that affect the risk of supply chain financial information. This article is divided into four categories, with reference to the relevant literature ${ }^{[5-7]}$, the specific analysis is as follows:

(1) Financing enterprise. Financing business analysis includes seven factors: First, the basic quality. The basic quality of the enterprise is the internal condition that affects the credit status of the enterprise. A higher quality of the enterprise can ensure that the enterprise continuously develops new products, expands new businesses, increases market share and obtains greater economic benefits. Second, profitability. Profitability is the ability to obtain profits in the course of business operation. It is the foundation of corporate credit, the concentrated expression of management level and business performance. Only when the enterprise is profitable, is it possible to repay its debts on schedule. Third, operational capacity. The operational capacity is the efficiency of capital utilization as reflected by the relevant indicators such as the turnover rate of production and operation funds of enterprises and indicates the ability to manage and use funds. Fourth, growth potential. Growth potential is to promote enterprises to continuously improve and improve the credit status of the force, only the growth potential of large enterprises to ensure the continuity of earnings, the credit will be good. Fifth, solvency. Corporate solvency is the most important manifestation of the credit status of an enterprise. It not only reflects the business risk but also reflects the ability of an enterprise to use its liabilities to carry out business activities. Sixth, credit history. Credit records are the performance status of the company in the past, not only reflects the company's solvency, but also an objective reflection of the enterprise's willingness to pay. Seventh, 
innovation ability. With the rapid development of science and technology, the ability of enterprise innovation plays a decisive role in forming a competitive advantage, especially for small and medium sized technology enterprises.

(2) Core enterprise. The core enterprises are in a strong position in the supply chain and can play a decisive role in the stability of the information flow, logistics and capital flow in the supply chain. The core enterprises have the power to make decisions on the supply chain. They have strict selection criteria and strong control over suppliers, distributors and downstream manufacturing enterprises. Supply chain finance in the design process based on the real trade background, often need to cooperate with the core business, including the docking of finance, to determine the historical operating settlement, a reasonable measure, the funds entrusted with the payment. Therefore, in supply chain finance, the investor's assessment is not focused on the financial status of the enterprise but on the status and financial status of the core enterprise in the supply chain and the competitiveness and management efficiency of the entire supply chain. The core business analysis mainly from six aspects, of which three basic indicators such as basic quality, profitability and solvency similar to the financing of enterprises. Take the next three indicators as follows: First, the status of the industry, the status of the industry the main study of the industry rankings, requiring outstanding industry position, the amount of sales in the forefront of the national counterparts. Second, the credit rating. Credit rating agencies use established symbols to identify the future ability of principals and debentures to repay debts and the level of likelihood of debt service. Third, the industry characteristics. Industry characteristics are particularly significant signs and symbols that distinguish an industry from other industries.

(3) Subordinate to the industry. The classification of industries refers to the detailed division of the organizations engaged in the production of the same nature in the national economy or other economic and social organizations or the structure of individual organizations and can explain the development stage of the industry itself and its position in the national economy. Business development and industry development are inseparable, the development of the industry is better, companies will develop better. Therefore, the development of the industry will affect the credit risk of supply chain finance. If an industry as a whole low level of development, the lack of competitiveness among enterprises in the industry, the state support for the industry will be less, the industry can not be optimistic about the future development of the supply chain in the development process is likely to be interrupted, the supply chain Financial credit risk is high. Industry risks are systemic risks and are mainly affected by factors such as the macroeconomic environment, policy and regulatory environment, industry conditions and development prospects. Conduct risk analysis of their respective industries and determine the life cycle stages of their respective industries as well as their sensitivity to economic changes. Industry risks reveal the impact of industry factors on business operations.

(4) Supply chain operation. The overall operation of the supply chain has a direct impact on the credit risk assessment of enterprises. Operating conditions are good, the transaction risk is small, can weaken the comprehensive credit risk of small-and-medium-sized enterprises. Analysis of the supply chain operations from the following aspects: First, the close cooperation. The level of cooperation is a measure of the length of cooperation between enterprises and the frequency of cooperation, reflecting the closeness between enterprises and the stability of cooperation. The longer the cooperation between the two parties takes, the higher the frequency of cooperation and the closer the cooperation are, the stronger the stability of cooperation is and the smaller the credit risk is. Second, related party transactions. To measure whether there is a related transaction with obvious price difference in the supply chain or a virtual transaction with inflated revenue, the related transaction has a greater impact on the credit risk assessment. Third, the degree of information. Information degree reflects whether the flow of information in the supply chain is smooth, including the degree of information sharing and the completeness of the information system, which directly affects the production flow, inventory control and distribution planning of enterprises. Fourth, supply chain performance. Supply chain performance evaluation focuses on input and output, reflecting the overall supply chain capacity, management and rapid response to 
market capacity; Fifth, the performance of the past. Past performance is to evaluate supply chain companies in the past cooperation credit indicators. The lower the ratio of defaults to the total number of transactions in past transactions, the better the credit status of the cooperation and the lower the credit risk.

\section{Establishment on Evaluation Index System for Supply Chain Finance Credit Risk}

The following principles should be followed in building an index system for credit risk evaluation of supply chain finance: First, the principle of comprehensiveness reflects the risk status of the financing enterprises in an all-round and realistic manner. The selected indicators must be comprehensive and cover all the factors that affect the credit risk. It is necessary to consider the macroeconomic environment and financing enterprises as well as the conditions of the core enterprises and the supply chain. It is necessary to consider the current situation as well as consider the future development. Second, the principle of science and the combination of various indicators need to form a system and highlight the hierarchy of the index system. The index, which describes the actual situation of the enterprise, rises to the index that summarizes the comprehensive situation of the enterprise, and the level is clear. Second, the principle of independence, as far as possible to exclude indicators with high correlation, to avoid the problem of not highlighting and duplication, the same category of indicators to avoid duplication of the underlying indicators, indicators of different indicators between the lower level to be independent. According to the supply chain financial information risk analysis, this article builds the supply chain financial information risk evaluation index system as shown in Fig 2.

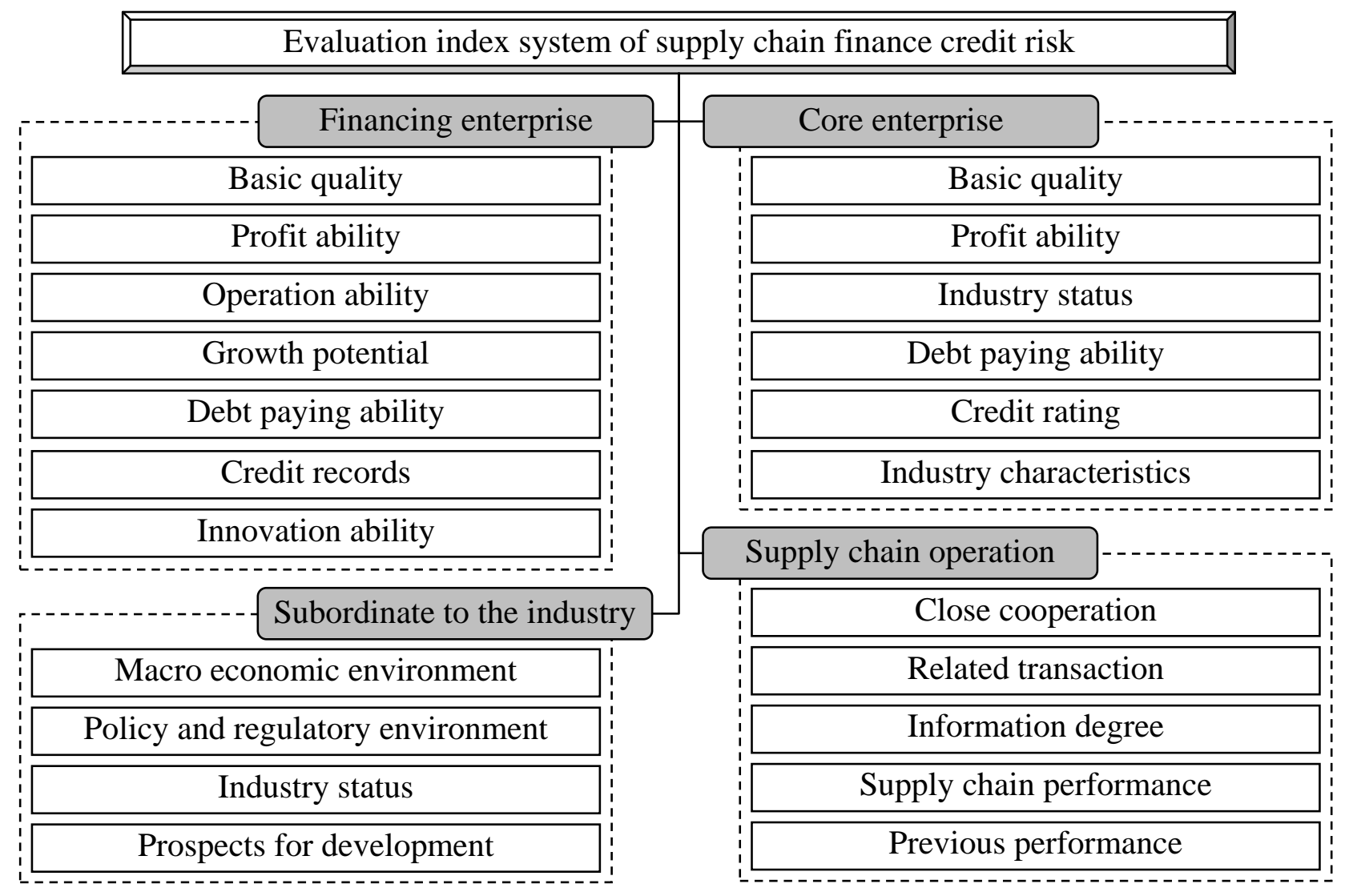

Fig 2 Composition on evaluation index system of supply chain finance credit risk

\section{References}

[1] Y. X. Chu, "Research on Supply Chain Finance Credit Risk Evaluation," Master's Dissertation of Shandong University of Finance and Economics, 201. 
[2] G. Y. Zhu, "Risk Control for Supply Chain Financing Businesses of TPL Enterprises," Logistics Technology, vol. 33, no. 17, pp. 329-331 2015.

[3] Y. Zhu, "Analysis of financial credit risk in supply chain," China International Business, vol. 10, no. 6, pp. 193-194, 2017.

[4] J. Y. Chen, "Supply chain financing and risk characteristics," Paper network: http://www. xzbu. com/7/view-6738765.htm, 2017-12-29.

[5] X. Xiong, J. Ma, W. J. Zhao, et al., "Credit Risk Analysis of Supply Chain Finance," Nankai Business Review, vol. 18, no. 4, pp. 92-98, 2009.

[6] Z. L. Guo, Q. Cui, "Research on Credit Risk Based on Supply Chain Finance," Value Engineering, vol. 36, no. 8, pp. 77-79, 2017.

[7] H. Liu, X. J. Ha, "A Construction and Empirical Analysis on Financial Risk of Supply Chain Based on Jiangsu Province," Value Engineering, vol. 35, no. 32, pp. 107-110, 2016. 